\title{
Strategi Pengembangan Agribisnis Kopi Untuk Mendukung Wisata Telaga Ngebel Ponorogo
}

\author{
Mila Diana Sari ${ }^{1}$, Amrih Yuwono ${ }^{2}$ \\ ${ }^{1}$ Fakultas Ekonomi, Universitas Merdeka Ponorogo, Jl. Pacar 30, Ponorogo, 63418 \\ E-mail: miladianasari.se@gmail.com \\ ${ }^{2}$ Fakultas Ekonomi, Universitas Merdeka Ponorogo, Jl. Pacar 30, Ponorogo, 63418 \\ E-mail: amrihyuwono.ay@gmail.com
}

\begin{abstract}
One of the natural attractions in Ponorogo is Ngebel lake. Increasing the tourist attraction of Ngebel Lake can be done by developing agribusiness around it. The coffee agribusiness in the Ngebel Lake area was developed traditionally so that it has not been able to support the development of the Ngebel Lake tourism park. On the other hand, to increase the attractiveness of a tourist park, it is necessary to support the management of the potential of the surrounding area. Therefore it is necessary to conduct a study on the strategy of developing coffee agribusiness so that the attractiveness of Lake Ngebel can be increased. The method used in this study is to analyze the potential of coffee agribusiness using a SWOT analysis so that the most strategic method in developing coffee agribusiness can be determined. The results showed that the coffee agribusiness in Gondowido Village could support Ngebel Lake agro-tourism through improving weaknesses by taking advantage of opportunities.
\end{abstract}

Keywords—: Strategy; coffee agribusiness; Ngebel lake.

\section{PENDAHULUAN}

Telaga Ngebel merupakan daerah wisata yang ada di kabupaten Ponorogo. Pengembangan obyek wisata tersebut dapat dilakuan dengan pengembangan potensi ekonomi lokal (Rahman dan Prakoso, 2012). Ekonomi lokal yang berpotensi dikembangkan adalah agribisnis kopi. Wisata telaga Ngebel berada di daerah pengunungan yang cocok untuk perkembangan perkebunan rakyat, diantaranya tanaman kopi. Tanaman kopi didaerah tersebut memiliki cita rasa yang khas sehingga dapat dijadikan salah satu daya tarik ntuk meningkatkan pengunjung didaerah wisata Ngebel.

Agribisnis kopi merupakan salah satu agribisnis yang memiliki daya tarik khas untuk dikembangkan di Indonesia (Alhidayat dan Liyanti, 2018). Agribisnis kopi di daerah Ngebel dikelola secara tradisional sehingga keberadaannya tidak mampu untuk mendukung perkembangan wisata Ngebel, disisi lain agribisnis kopi memiliki potensi untuk dikembangkan sehingga perlu dilakukan kajian untuk menentukan strategi pengembangan agribisnis kopi sehingga dapat mendukung pengembangan wisata Ngebel. Tujuan penelitian ini adalah mencari stretegi yang dapat dikembangkan di agribisnis kopi dengan cara memaksimalkan faktor yang sudah ada di daerah tersebut.

Hasil penelitian ini dapat digunakan dasar dalam pengembangan danau Ngebel melalui penataan atau pengembangan potensi disekitar wilayah danau Ngebel, sehingga pembangunan didaerah wisata Ngebel dapat terintegrasi dengan pengembangan daerah disekitarnya. Stratei pengembangan agribisnis kopi dapat dijadikan sarana untuk meningkatkan pendapatan petani ngebel dan menciptakan lapangan usaha bagi generasi muda yang akan menekuni bidang perkebunan kopi.

\section{METODE PENELITIAN}

Penelitian dilakukan dengan pengambilan data sekunder mengenai potensi daerah dalam agribisnis kopi meliputi diskripsi daerah untuk pengembangan agribisnis kopi. Selanjutnya dilakukan pengambilan data primer melalui kegiatan survey terhadap pihak yang berhubungan dengan aktivitas agribisnis kopi. Data yang terkumpul dilakukan tabulasi dan didiskusikan dengan pakar yang ahli dalam agribisnis kopi. Sealain itu data juga dilakukan analisa SWOT untuk mendapatkan strategi dalam pengembangan agribisnis kopi untuk mendukung daya tarik wisata Ngebel.

Penelitian ini merupakan penelitian kualitatif dengan pendekatan pengalaman manusia terhadap gejala dan pengalaman yang dialami. Penelitian dilakukan di desa Gondowido kecamatan ngebel kebupaten Ponorogo. Desa ini merupakan desa sentra kopi di sekitar telaga Ngebel. Sampel penelitian ditentukan dengan metode purposive sampling dengan menggali informasi dari kepala desa, ketua kelompok tani, Dinas pertanian. Dari informasi awal maka dikembangkan untuk mencari informasi lebih detail tentang obyek permasalahan yang perlu didalami lebih mendalam.

Data yang akan dikumpulkan dibedakan menjadi 2 yaitu data sekunder dan data primer. Data sekunder berupa dokumen, publikasi, arsip dan foto. Data primer diperoleh dengan teknik observasi dan wawancara. Data yang terkumpul dilakukan analisa data melalui metode SWOT sehingga didapatkan strategi pengembangan agribienis kopi untuk mendukung wisata danau Ngebel. 
Website : http://agritek.unmermadiun.ac.id/index.php/agritek

\section{III.HASIL DAN PEMBAHASAN}

\section{A. Keadaan umum Kecamatan Ngebel}

Luas lahan Kecamatan Ngebel adalah 59,51 km², lahan di Kecamatan Ngebel terbagi menjadi lahan pertanian seluas 28,83 $\mathrm{km}^{2}(48,45 \%)$ dan lahan non pertanian seluas $30,68 \mathrm{~km}^{2}(51,55 \%)$. Penggunaan lahan non pertanian sebagian besar masih hutan negara yaitu18,27 km² (59,56\%) untuk bangunan dan halaman sekitar 12,25 km² (39,93\%), lainnya (jalan, sungai, lahan tandus, lapangan dan pekarangan) seluas 15,68 hektar (0,51\%).Formasi tanah pada Kecamatan Ngebel adalah batuan vulkanik muda sedangkan jenis tanahnya merupakan komplek mediteran dan litosol yang peka terhadap erosi, tetapi memiliki sifat tanah yang subur, maka dari itu sebanyak 73,46\% penduduknya bermatapencaharian pada bidang pertanian (Abdulah, 2016) . Pariwisata di telaga Ngebel merupakan aset yang perlu ditingkatkan melelui perbaikan sarana dan prasaarana (Mustikawati et al., 2017) . Pengembangan pariwisata memiliki tujuan meningkatkan pendapatan masyarakat dan mensejahterakan masyarakat, mendukung kelestarian lingkungan, mengembangkan perekonomian, dengan meminimalkan dampak negatif. (Papatungan et al, 2017)

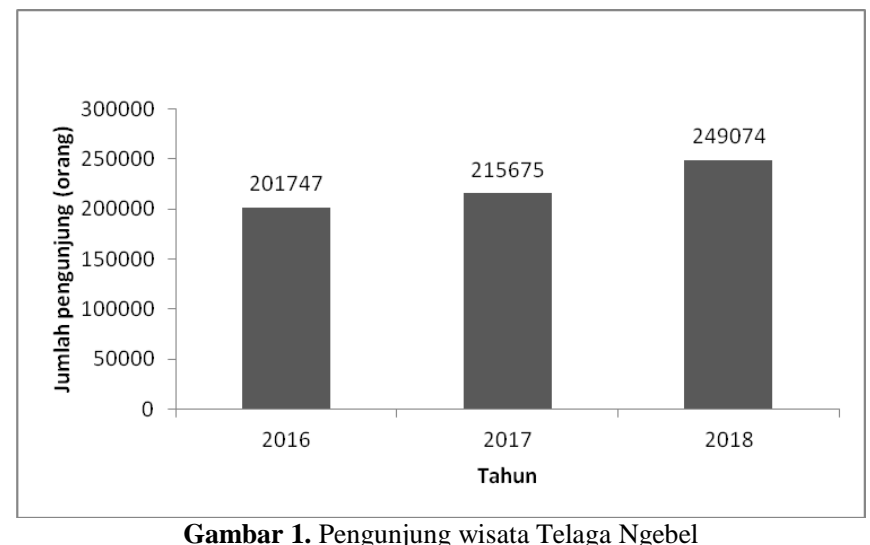

Internal Factor Evaluation (IFE)

Faktor internal di desa Gondowido perlu dikaji untuk mengetahui sisi kekuatan dan kelemahan yang dimiliki petani kopi di desa Gondowido. Informasi kondisi internal diperoleh dari wawancara dengan petani kopi dan perangkat desa yang berhubungan dengan petani kopi. Faktor internal yang dikaji adalah daya tarik kopi, sarana dan prasarana, luas lahan, budidaya, pasca panen. Hal ini berbeda dengan didaerah Gayo, faktor internal yang dimiliki petani dalam usaha pengembangan usahatani kopi Gayo dengan faktor kekuatan bobot tertinggi yaitu ketersediaan lahan yang cukup dan faktor kelemahan dengan bobot tertinggi yaitu petani kekurangan modal dan tidak mengetahui hasil - hasil penelitian kopi Faktor eksternal yang dihadapi petani kopi dalam pengembangan usahatani kopi Gayo adalah faktor peluang dengan bobot tertinggi yaitu adanya perdagangan bebas yang membuat kopi gayo terkenal. Dan peluang dengan bobot tertinggi yaitu terdapat perubahan harga kopi Gayo. Beberapa alternatif strategi yang dapat dilakukan dalam usaha pengembangan usahatani (utami et al., 2014)

Berdasarkan perhitungan matrik IFE maka yang menjadi kekuatan utama adalah citra rasa kopi dngan skor 0,342, sedangkan faktor kekuatan yang terkecil adalah jarak dengan obyek wisata dengan skor 0,041. Kelemahan yang paling besar adalah keterbatasan anggaran dengan skor 0,560 dan kelemahan yang terkecil adalah akses kelokasi dengan skor 0,119 (Tabel 1). Hal ini berbeda dengan penelitian Hariance et al, ( 2016) yang menyatakan bahwa agrowisata kopi di tentukan tersedianya lahan yang cukup luas, sumberdaya manusia sebagai tenaga kerja

Tabel 1. Matrik IFE Kopi Gondowido

\begin{tabular}{rlrrr}
\hline No & Faktor strategi internal & Bobot & Rating & Skor \\
\hline \multicolumn{4}{c}{ Kekuatan } \\
1 & Kepemilikan lahan & 0,100 & 2,53 & 0,253 \\
2 & Luas lahan & 0,110 & 2,58 & 0,284 \\
3 & Jarak dengan obyek wisata & 0,040 & 1,02 & 0,041 \\
4 & Cita rasa kopi & 0,120 & 2,85 & 0,342 \\
5 & Teknologi budidaya & 0,050 & 1,13 & 0,057 \\
\hline Sub total & & & 0,976 \\
\hline
\end{tabular}

Kelemahan

Volume 21 Nomor 2 September 2020, AGRI-TEK | 69 
Website : http://agritek.unmermadiun.ac.id/index.php/agritek

\begin{tabular}{rllll}
1 & Proses pasca panen & 0,11 & 2,70 & 0,297 \\
2 & Rantai pemasaran & 0,12 & 3,00 & 0,360 \\
3 & Akses lokasi & 0,07 & 1,70 & 0,119 \\
4 & Keterbatasan anggaran & 0,15 & 3,73 & 0,560 \\
5 & Sumberdaya manusia & 0,13 & 3,07 & 0,399 \\
\hline Sub total & & & 1,735 \\
\hline Total & 1,00 & & $-0,759$ \\
\hline
\end{tabular}

Berdasarkan perhitungan matrik EFE maka yang menjadi peluang utama adalah perkembangan wisaa ngebel dengan skor 0,560 , sedangkan faktor peluang yang terkecil adalah akses permodalan dengan skor 0,042. Ancaman yang paling besar adalah banyaknya kopi insan dengan skor 0,409 dan ancaman yang terkecil adalah kopi dari daerah lain dengan skor 0,16 (Tabel 2)

Tabel 2. Matrik EFE Kopi Gondowido

\begin{tabular}{|c|c|c|c|c|}
\hline No & Faktor strategi Eksternal & Bobot & Rating & Skor \\
\hline \multicolumn{5}{|c|}{ Peluang } \\
\hline 1 & Dekat lahan perhutani & 0,110 & 3,02 & 0,332 \\
\hline 2 & Ketersedian tenaga kerja & 0,050 & 1,47 & 0,074 \\
\hline 3 & Program pemerintah & 0,040 & 1,13 & 0,045 \\
\hline 4 & Permintaan pasar & 0,100 & 2,95 & 0,295 \\
\hline 5 & Perkembangan wisata Ngebel & 0,140 & 4,00 & 0,560 \\
\hline 6 & Akses permodalan & 0,040 & 1,05 & 0,042 \\
\hline 7 & Tenaga ahli & 0,040 & 1,07 & 0,043 \\
\hline \multicolumn{4}{|c|}{ Sub total } & 1,391 \\
\hline \multicolumn{5}{|c|}{ Ancaman } \\
\hline 1 & Banyak kopi instan & 0,12 & 3,41 & 0,409 \\
\hline 2 & Kopi dari daerah lain & 0,07 & 2,08 & 0,146 \\
\hline 3 & Bencana alam & 0,09 & 2,38 & 0,214 \\
\hline 4 & Alih fungsi lahan & 0,10 & 2,73 & 0,273 \\
\hline 5 & Hama dan penyakit tanaman & 0,10 & 2,78 & 0,278 \\
\hline \multicolumn{3}{|c|}{ Sub total } & & 1,320 \\
\hline Tot & & 1,00 & & 0,071 \\
\hline
\end{tabular}

\section{B. Analisis SWOT}

Teknik anlisa dengan menggunakan SWOT dilakukan untuk mengkaji peluang pengembangan agrowisata kopi di desa Gondowido. Komponen analisa SWOT berupa kekuatan, kelemahan, peluang dan ancaman. Keempa komponen tersebu dapat dipadukan untuk menghasilkan arahan pengembangan agrowisata kopi (Toguria et al, 2013).

Berdasrakan faktor internel agrowisata kopi menunjukan bahwa nilai kekuatan 0,976 dan nilai kelemahan menunjukkan 1,735. Selisih nilai kekuatan dan kelemahan digunakan untuk menentulkan sumbu X. Berdasarkan tabel faktor eksternal agrowisata Ngebel didapatkan bahwa faktor peluang adalah 1,391 dan faktor ancaman adalah 1,320. Selisih faktor peluang dengan ancaman digunakan sebagai sumbu $\mathrm{Y}$.

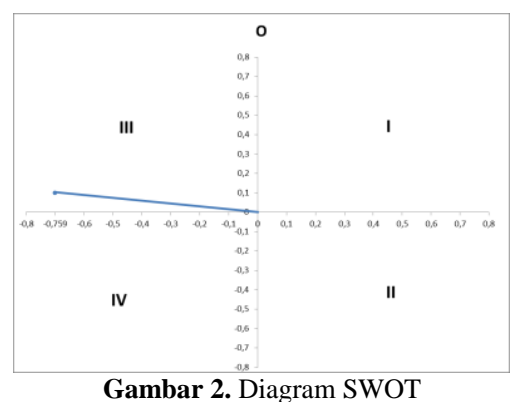

Volume 21 Nomor 2 September 2020, AGRI-TEK | 70 
Website : http://agritek.unmermadiun.ac.id/index.php/agritek

Berdasarkan gambar 2 diketahui bahwa posisi agrowisata kopi di Gondowido berada di kwadran III maka strategi pengembangan agrowisata kopi di Gondowido dengan cara mengelola kelemahan dengan memanfaat peluang yang ada. Kelemahan agrowisata kopi yaitu keterbatasan anggaran dan sumberdaya manusia, sedangkan peluang yang ada yaitu perkembangan wisata gebel dan permintaan pasar. Hasil penilaian ini berbeda dengan penelitian Alhidayat dan Liyanti, (2018) yaitu faktor internal didapatkan nilai 0,35 . Penilaian faktor eksternal didapatkan nilai $-0,11$. Dari nilai tersebut dapat diketahui strategi yang harus diterapkan dalam kondisi ini adalah strategi ST (Strenghts- Threats), yaitu; 1) Menetapkan strategi harga pasar untuk menghadapi persaingan; 2) Meningkatkan kegiatan promosi dan periklanan; 3) Inovasi produk; 4) Penerapan standar mutu produk.

Strategi yang perlu dilakukan dalam pengembangan agrobisnis kopi untuk mendukung wisata telaga Ngebel melalui:

1. Meningkatan kemampuan sumber daya manusia.

Peningkatan sumberdaya manusia dapat dilakuakan dengan peningkatan kemampuan petani kopi dalam mengembangkan komoditas kopi di Gondowido. Kegiatannya dapat dilakukan dengan program pelatihan dan studi banding pada daerah penghasil kopi yang lebih dahulu berkembang

2. Diversifikasi produk kopi

Inovasi produk kopi dapa dilakukan melalui pencipataan produk produk kopi yang berbeda dan memiliki cirikas tertentu, sehingga bran kopi Gondowido dapat mudah dikenal masyarakat terutama pengunjung di telaga Ngebel.

3. Efesiensi proses

Peningkatan kemampuan sumberdaya dalam efesiensi proses sehingga didapakan biaya produksi yang lebih rendah tanpa mengurangi mutu dan cita rasa kopi Gondowido. Salah satu kegiatan yang dapat dilakukan adalah pembukaan oule disekiar telaga Ngebel.

4. Bekerjasama dengan perbankan

Di Kecamatan Ngebel sudah tersedia kantor BRI , namun keberadaannya masih belum termanfaatkan secara maksimal, sehingga perlu pendampingan dalam mengakses perbankan unuk kemajuan agrobisnis kopi di Gondowido.

5. Pengelolaan dana PUAP

Gapoktan di Desa Gondowido telah mendapatkan dana PUAP sehingga pemanfaatannya harus dimaksimalkan dalam mendukung agrobisnis kopi terutama dalam pemasaran hasil kopi.

\section{IV.KESIMPULAN}

Agribisnis kopi di Desa Gondowido dapat mendukung agrowisata Telaga Ngebel melalui perbaikan kelemahan dengan memanfaatkan peluang. Kelemahan agrowisata kopi yaitu keterbatasan anggaran dan sumberdaya manusia, sedangkan peluang yang ada yaitu perkembangan wisata gebel dan permintaan pasar. Strategi yang dapat diterapkan yaitu peningkatan sumberdaya manusia, diversifikasi kopi, efesiensi proses, bekerjasama dengan perbangkan dan pengelolaan dana PUAP.

\section{DAFTAR PUSTAKA}

Abdulah FA, 2016. Pendekatan SWOT Dalam Pengembangan Obyek Wisata Telaga Ngebel Di Kabupaten Ponorogo. Jurnal ilmiah mahasiswa ekonomi dan bisnis Vol 4 No 1.

Alhidayat R, Liyanti R, 2018. Strategi pengembangan industri kecil pengolahan kopi bubuk di kabupaten Kepahiang provinsi Bengkulu. Jurnal Aghinya Stiesnu Bengkulu Volume 1 Nomor 1.

Hariance R, Febriamansyah R, dan Tanjung F, 2016. Strategi pengembangan agribisnis kopi robusta di kabupaten solok. AGRISEP Vol 15 No.1 1: 111 - 126

Mustikawati TA, Sunarti, Pangestuti E, 2017. Analisis pengembangan sarana prasarana obyek wisata alam telaga Ngebel dalam meningkatkan kesejahteraan ekonomi masyarakat. Jurnal Administrasi Bisnis (JAB) Vol. 53 No.2 : 1- 10

Paputungan HF, Tamod, ZE, Pio, DD, 2017. Strategi pengelolaan agrowisata kebun kopi di desa Purworejo Timur, kabupaten Bolaang Mongondow Timur. Agri-SosioEkonomiUnsrat, Vol 13 No 3, : $77-86$

Rahman N, Prakoso HBS, 2012. Perspektif Stakeholders terhadap Potensi Obyek Dan Daya Tarik wisata (Odtw) Telaga Ngebel Kabupaten Ponorogo. Jurnal Bumi Indonesia.

Toguria NR, Chalil D, Sinar Indra Kesuma SI, 2013. Strategi pengembangan agribisnis kopi Mandailing (Coffea arabica) Studi Kasus : Desa Simpang Banyak Julu, Kecamatan Ulu Pungkut, Kabupaten Mandailing Natal. Journal of Agriculture and Agribusiness Socioeconomics.

Utami K, Salmiah, Dan Fauzia L, 2014. Strategi pengembangan usaha tani kopi arabica ( coffea sp ) di kabupaten Gayu ( Studi Kasus ; Desa Cane Baru Kecamatan Pantan Cuaca ). Journal of Agriculture and Agribusiness Socioeconomics. 